Oladele S Olatunya

Adefunke O Babatola

Adewuyi T Adeniyi

Adebukola B Ajite

Isaac O Oluwayemi

Ezra O Ogundare

Odunayo A Fatunla

Akinwumi K Komolafe

Adekunle B Taiwo

Alfred Airemionkhale

Ayotunde E Ajibola

Boluwatife A Sola-

Oniyide

Adewale O Adebisi

Benjamin F Ilori

Oyeku A Oyelami

DOI:http://dx.doi.org/10.4314/njp.v48i2.2

Accepted: 31st January 2021

Oladele S Olatunya (《)

Adefunke O Babatola,

Adewuyi T Adeniyi,

Adebukola B Ajite,

Isaac O Oluwayemi,

Ezra O Ogundare,

Department of Paediatrics,

College o f Medicine,

Ekiti State University,

Ado Ekiti, Ekiti State, Nigeria

Email: Ladeletunya@Yahoo.Com

Odunayo A Fatunla,

Akinwumi K Komolafe,

Adekunle B Taiwo,

Alfred Airemionkhale,

Ayotunde E Ajibola,

Boluwatife A Sola-Oniyide,

Adewale O Adebisi,

Benjamin F Ilori,

Department of Paediatrics, Ekiti

State University Teaching Hospital,

Ado-Ekiti, Nigeria.

Oyeku A Oyelami

Department of Paediatrics and

Child Health,

Obafemi Awolowo University,

Ile -Ife, Nigeria

\title{
CC $-\mathrm{BY}$ \\ Paediatric brought-in-dead at a tertiary health facility in South western Nigeria: Patterns and drivers
}

\begin{abstract}
Background: 'Broughtin-dead' (BID) refers to the demise of an individual before presentation to a health facility. This study assessed the pattern of paediatric BID cases seen at a tertiary health facility in southwest

Nigeria.

Method: A cross-sectional, descriptive study was done at the Children Emergency Ward (CEW) of the hospital between January 2014 and December 2018. The patterns of BID cases and presumed causes of death were determined using a standardized checklist adapted from the WHO verbal autopsy instrument. Results: Ninety-eight BID cases were seen during the study, constituting $2.5 \%$ of total patients seen during the period. The median (IQR) age of cases was 24.0 (8.75 - 63.0) months and $72.4 \%$

tis 19(19.4) and aspiration 17 $(17.3 \%)$ were the most common causes of death. The median (IQR) duration of illness before presentation was $3.0(1.0-7.0)$ days but most presented from $4-7$ days of illness. A significant relationship was found between the duration of illness and whether or not prehospital treatment was received ( $\mathrm{p}$ $<$ 0.0001). Unprescribed drugs purchased over the counter were the most commonly used treatment in $79.1 \%$ of cases ( $p<0.0001)$.

Conclusion: This study has highlighted the prevalence and pattern of paediatric BID in a tertiary health facility in southwest Nigeria and the factors that were associated with it. More efforts need to be geared towards community sensitization and pediatric health care to prevent factors drivingits menace.
\end{abstract} were under-fives. Most had symptoms related to the haematologic $(36.7 \%)$, respiratory $(24.5 \%)$ or digestive $(20.4 \%)$ systems. Severe anaemia 31(31.6\%), gastroenteri-
Keywords: Pediatric Brought-in Dead; Pattern; Drivers; Nigeria. 


\section{Introduction}

Brought-in-dead (also known as dead-on-arrival, or dead -before-arrival) is a term used to describe patients who were assessed by an attending physician to have no sign of life at the time of presentation to a health facility. ${ }^{1}$ Unlike the mortality rate in the emergency room (ER) which could serve as an assessment of quality of health care offered at a health facility, the prevalence of BID gives an idea of prehospital and community factors affecting health and health care. ${ }^{1}$

Vital statistics, which include records of number and causes of death, are important for health care planning, policy formulations, monitoring and evaluation. ${ }^{2,3}$ In ideal situations, every death should be recorded. In many developing countries, however, records are not usually kept of deaths occurring outside the hospital setting, including BID. This creates some inaccuracy in their vital statistics and impairs appropriate policy formulations. ${ }^{2}$ There is therefore a need for physicians to pay attention to this largely submerged section of the iceberg in our vital statistics. A study from a tertiary health facility in Nepal reported 7 BIDs among pregnant women, a number that was almost double the four deaths recorded among the in-patients over the same period. $^{4}$ In a report from southwest Nigeria, $11.1 \%$ of adult ER mortality over 5 years were BIDs. ${ }^{5}$ A much higher prevalence of $31.1 \%$ of total ER mortality (across all age groups including infants and the elderly) was reported from a study in Ghana. ${ }^{1}$ Yokobori et $a l^{6}$ reported 1378 and 209 BID cases in adults and children respectively in a tertiary health care facility in Zambia over an 8-month period. The prevalence of BID in a health care facility is influenced by a number of factors that include the level of health facility (primary, secondary or tertiary), presence and number of other health care facilities in the same geographical area and extant laws of the state (for example, requirement for death certificate for permission for burial). ${ }^{6}$

Verbal autopsy (VA) is a method of determining the cause of death of deceased individuals through information obtained about the course and circumstances surrounding their illness before demise. ${ }^{7}$ The World Health Organisation (WHO) recommends VA for use in instances when medical diagnosis and certification of cause of death is not feasible. ${ }^{8}$ Verbal autopsy in medical practice finds a great use when a medical diagnosis is not available because the attending physician has not had any prior involvement in the care of the deceased patient as obtainable in cases of BID. ${ }^{9}$

Few reports on BID have been published in the paediatric age group and none from our study locality. This study aims to study the prevalence, patterns, and drivers of cases of paediatric BID in a tertiary health facility in southwest Nigeria using VA. It is hoped that the findings from the study may help in policy formulation for the study area and possibly, stimulate reports from other health facilities on this relatively poorly reported phenomenon.

\section{Methods \\ Study design and setting}

The study was a descriptive, cross-sectional study conducted over a five-year period (January 2014 and December 2018 at the Children Emergency Ward (CEW) of the Ekiti State University Teaching Hospital Ado Ekiti. The study location is a tertiary health care facility located in southwest Nigeria. It provides specialized health care for the residents of the State and referrals from neighbouring states. The CEW of the hospital is a 12-bedded ward staffed with different cadres of health workers including nursing staffs, interns, resident doctors, supervising consultants and other ancillary/ supporting workers. The resident doctors are usually the frontline physicians who receive and attend to patients after initial triage by the nursing staff. Children presenting with acute illnesses requiring emergency treatment are admitted for resuscitation and initial treatment at the ward after which they are either discharged or transferred from the CEW to other paediatric wards depending on their clinical responses and or health care needs.

\section{Study population}

This included all children who were brought into the CEW of the hospital over the study duration and were confirmed dead at presentation.

\section{Data collection and study instrument}

A standardised checklist (verbal autopsy form) adapted from the WHO 2012 verbal autopsy instrument was used to obtain relevant information from the caregivers of the patients as well as document physical examination findings of the physician who received the body and certified the patient dead. Briefly, the form has sections on personal information (sociodemographic data), observed symptoms and signs, history of symptoms, injuries, health services/treatments received and where such was given, pertinent physical examination finding of the attending physician and suspected likely cause (s) of death of the patients. The form was pretested at the adult emergency ward of the hospital before being used for the study.

The resident doctors filled the forms and obtained relevant information about the age, gender, onset, progression and duration of symptoms, details about treatments given prior to demise and where treatments were received. The socioeconomic class of the care-givers was determined using their occupation and highest level of formal education as described by Oyedeji. ${ }^{10}$

Physical examination was done on each patient to look for signs to suggest the likely diagnosis/cause of death. 
These included examination for skin changes (discolouration, bleeding, swelling), jaundice, lymph node enlargements, abdominal palpation for organ enlargement and performance of post-mortem lumbar puncture when indicated and permitted by the caregivers to exclude meningitis in suspected cases. Severe anaemia was assumed to be the cause of death only if the caregiver noticed pallor and the child had clinical features of anaemia prior to demise. Similarly, sepsis was assumed to be the cause of death if child`s symptoms had involved multiple body systems. Other causes were as suggested by symptoms, illness history and physical examinations.

Caregivers of the patients were counselled for postmortem examination to determine the cause of death. They were also counselled on the suspected cause of death and steps to prevent similar occurrences in other children.

\section{Ethical considerations}

To maintain confidentiality, the checklist form did not show the names of the deceased and the details obtained on verbal autopsy were carefully kept by the researchers. Ethical approval for the study was obtained from the Ethics and Research Committee of the Institution.

\section{Data analysis}

The Graph Pad Prism Program, version 5 for Windows (San Diego, California, USA) was used to perform the statistical analysis. Cases were grouped according to the body system most predominantly affected based on the predominant symptoms and suspected major primary cause of death and diagnosis. Also, they were grouped for further analysis according to their symptoms duration and whether they had received any treatment (s) prior to presenting at our facility and where such treatment was given. Continuous data were described with median and interquartile range as these were not normally distributed. Categorical data were summarized using percentages and proportions and comparisons between proportions were made using Fisher`s Exact or Chi-square test as appropriate. Statistical significance was set at $\mathrm{p}$ value $<0.05$.

\section{Results \\ Demographic characteristics of the cases}

A total of 98 children were recruited as BID during the study period. This represents $2.5 \%$ of the 3,960 patients who presented at the CEW over the same period. The yearly number of BIDs seen are shown in Figure 1 with the lowest and highest cases recorded in 2017 and 2018 respectively. A total of 264 deaths were recorded among children admitted and managed at the CEW over the 5year period thus representing a $6.7 \%$ mortality rate.
Fig 1: Yearly cases of brought- in- dead

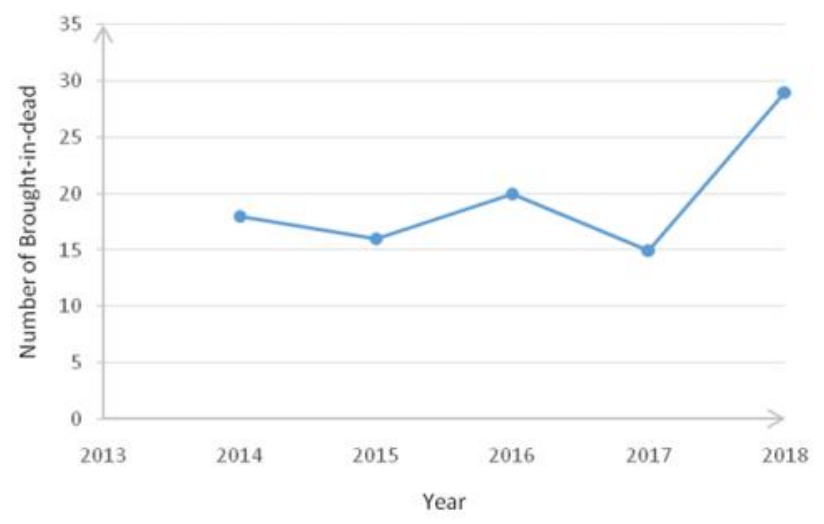

The age of the patients ranged between 28 hours and 144 months, with a median (IQR) age of $24.0(8.75-63.0)$ months. Seventy-one $(72.4 \%)$ were under-fives and only $3(3.1 \%)$ were older than 10 years. Male to female ratio was 1.04:1. Most of the cases $(65.1 \%)$ were in the lower social class (Table 1$)$.

\begin{tabular}{llll}
\hline \multicolumn{3}{l}{ Table 1: Demographic characteristics of the cases of BID } \\
Characteristics & Variable & Frequency & Percentage \\
& & $\mathrm{N}$ & $\%$ \\
\hline Gender & Male & 50 & 51.0 \\
& Female & 48 & 49.0 \\
Age group & Total & 98 & 100.0 \\
& $<5$ years & 71 & 72.4 \\
& $5-10$ years & 24 & 24.5 \\
& $>10$ years & 3 & 3.1 \\
Social class & Total & 98 & 100.0 \\
& Upper & 7 & 8.1 \\
& Middle & 23 & 26.7 \\
& Lower & 56 & 65.1 \\
& Total & 98 & 100.0 \\
\hline
\end{tabular}

Distribution of cases and symptoms according to body systems

The haematologic, respiratory and digestive systems were the most commonly affected systems, in 36 (36.7\%), 24 (24.5\%), 20 (20.4\%) of cases respectively. The commonly reported symptoms included fever, pallor, jaundice, respiratory distress, diarrhoea and vomiting (Figure 2).

Fig 2: Distribution of causes of death according to body systems.

\section{Cases and symptoms By Systems}

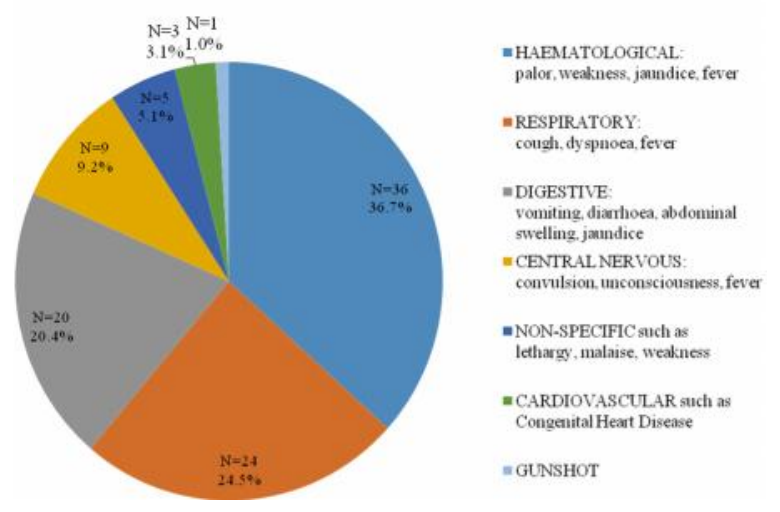




\section{Suspected causes of death among the cases}

As shown in Table 2, severe anaemia, acute gastroenteritis, aspiration and sepsis accounted for $31.6 \%$, $19.4 \%, 17.3 \%$ and $15.3 \%$ of the suspected cause of death among the cases. Eight $(8.2 \%)$ cases died from home accidents, which included two cases each of drowning, and burn injuries. Also, there was one case of poisoning with carbon monoxide from generator fumes and one case of accidental ingestion of pesticide. There was one case of gunshot injury involving two siblings while playing with neighbor's Dane gun and one case of severe head injury during home play. Three cases $(3.1 \%)$ had suspected cerebral malaria after exclusion of meningitis following post-mortem lumbar puncture. Other identified suspected causes of death included severe pneumonia and Steven-Johnson syndrome (1\% each).

\section{Causes of death according to age group}

Severe anaemia was the most common suspected cause of death across all the age groups, constituting 24 $(33.8 \%)$ among the under-fives, six $(25.0 \%)$ among the $5-10 y e a r$ olds and one $(33.3 \%)$ among those older than 10 years. Other leading causes of death among the under -fives were gastroenteritis $13(18.3 \%)$ and aspiration 14 $(19.7 \%)$. Gastroenteritis and sepsis were the leading causes among 5 - 10-year olds and this represented $20.8 \%$ each. A wider variety of causes of death were identified among those less than ten years than older patients. Details of these are shown in Table 2.

\begin{tabular}{|c|c|c|c|c|}
\hline $\begin{array}{l}\text { Suspected cause of } \\
\text { death }\end{array}$ & $\begin{array}{l}<5 \text { years } \\
\mathrm{N}=71\end{array}$ & $\begin{array}{l}5-10 \\
\text { years } \\
N=24\end{array}$ & $\begin{array}{l}11-15 \\
\text { years } \\
\mathrm{N}=3\end{array}$ & $\begin{array}{l}\text { Total } \\
\mathrm{N}=98\end{array}$ \\
\hline Severe anaemia & $24(33.8)$ & $6(25.0)$ & $1(33.3)$ & $31(31.6)$ \\
\hline Gastroenteritis & $13(18.3)$ & $5(20.8)$ & $1(33.3)$ & $19(19.4)$ \\
\hline Aspiration & 14 (19.7) & $3(12.5)$ & $0(0.0)$ & $17(17.3)$ \\
\hline Sepsis & $9(12.8)$ & $5(20.8)$ & $1(33.3)$ & $15(15.4)$ \\
\hline Home accident & $4(5.6)$ & $4(12.5)$ & $0(0.0)$ & $8(8.2)$ \\
\hline Cerebral malaria & $2(2.8)$ & $1(4.2)$ & $0(0.0)$ & $3(3.1)$ \\
\hline $\begin{array}{l}\text { Congenital heart } \\
\text { disease }\end{array}$ & $1(1.4)$ & $0(0.0)$ & $0(0.0)$ & $1(1.0)$ \\
\hline Severe pneumonia & $1(1.4)$ & $0(0.0)$ & $0(0.0)$ & $1(1.0)$ \\
\hline Birth asphyxia & $1(1.4)$ & $0(0.0)$ & $0(0.0)$ & $1(1.0)$ \\
\hline Hypoglycaemia & $1(1.4)$ & $0(0.0)$ & $0(0.0)$ & $1(1.0)$ \\
\hline $\begin{array}{l}\text { Steven Johnson } \\
\text { Syndrome }\end{array}$ & $1(1.4)$ & $0(0.0)$ & $0(0.0)$ & $1(1.0)$ \\
\hline
\end{tabular}

Numbers in parentheses represent percentages along the column

\section{Duration of illness prior to presentation}

The duration of illness in the patients prior to presenting as BID ranged from 1 to 60 days, with a median (IQR) duration of $3.0(1.0-7.0)$ days. Twenty-one $(21.4 \%), 19$ (19.4\%), $25(25.5 \%), 14(14.3 \%)$ and $19(19.4 \%)$ cases presented within 24 hours, $24-72$ hours, $4-7$ days, $8-$ 14 days and more than 14 days respectively. No statistically significant relationship was found between the duration of illness before presentation and age range, gender or social class of the cases.

\section{Relationship between duration of symptoms and whether or not treatment was given}

Information regarding whether or not, treatment was sought and given during the illness prior presentation, were volunteered by caregivers of 91 patients. Twentyfour $(26.4 \%)$ of these caregivers claimed not to have sought or given any form of treatment in the course of the child's illness. These included six of the eight patients who died from home accidents. A statistically significant difference was found between the duration of illness before presentation and whether or not any treatment was given $(p<0.001)$ as those who did not receive any pre-presentation treatment were more among patients with symptoms duration of less than 24hours and greater than 14days Table 3.

\begin{tabular}{|c|c|c|c|c|c|}
\hline $\begin{array}{l}\text { Duration of } \\
\text { symptoms }\end{array}$ & $\begin{array}{l}\text { Treatment } \\
\text { given } \\
\mathrm{N}(\%)\end{array}$ & $\begin{array}{l}\text { Treatment } \\
\text { not given } \\
\mathrm{N}(\%)\end{array}$ & Total & $x^{2}$ & $\mathrm{p}$-value \\
\hline $\begin{array}{l}\text { Less than } 24 \\
\text { hours }\end{array}$ & $11(16.4)$ & $9(37.5)$ & 20 & & \\
\hline $24-72$ hours & $17(25.4)$ & $2(8.3)$ & 19 & 30.1 & $<0.0001 \dagger$ \\
\hline $4-7$ days & $23(34.3)$ & $2(8.3)$ & 25 & 5 & \\
\hline $8-14$ days & $13(19.4)$ & $1(4.2)$ & 14 & & \\
\hline $\begin{array}{l}\text { More than } 14 \\
\text { days }\end{array}$ & $3(4.5)$ & $10(41.7)$ & 13 & & \\
\hline Total & $67(100.0)$ & $24(100.0)$ & 91 & & \\
\hline
\end{tabular}

NB: Test statistics $\dagger=$ Chi-square, Seven cases with no information regarding whether treatment was given were not included in the analysis

Among the 67 patients who sought treatment, treatment was sought from Patent and Proprietary Medicine Vendors (PPMVs) in 51 (76.1\%) cases and these involved the use of sundry drugs and interventions. Eleven $(16.4 \%)$ received treatment at traditional and other faithbased centres. These included $8(11.9 \%)$ at traditional home involving the use of herbal concoction in $6(9.0 \%)$ and scarification in $2(3.0 \%)$ cases. Three $(4.4 \%)$ cases were involved with other faith-based centres where prayers alongside drugs and herbal medicine were used in one case and the remaining two cases respectively. Some health care facilities were involved with 5 (7.5\%) cases. However, a significantly higher proportion of those who used self-prescribed over-the-counter drugs purchased them from the PPMVs $(\mathrm{p}=<0.001)$ Table 4 


\begin{tabular}{|c|c|c|c|c|c|}
\hline & Drugs & $\begin{array}{l}\text { Herbal } \\
\text { concotion } \\
\text { and or } \\
\text { scarifica- } \\
\text { tion }\end{array}$ & $\begin{array}{l}\text { Total }^{\mathrm{b}} \\
\mathrm{N}(\%)\end{array}$ & $x^{2}$ & $\begin{array}{l}\mathrm{p} \\
\text { valu } \\
\mathrm{e}\end{array}$ \\
\hline $\begin{array}{l}\text { Drug dispensary } \\
\text { (PPMVs) stores }\end{array}$ & 47 & 4 & $51(76.1)$ & & \\
\hline Other Hospitals & 5 & 0 & $5(7.5)$ & 39.20 & $\begin{array}{l}<0.0 \\
001 \dagger\end{array}$ \\
\hline $\begin{array}{l}\text { Traditional } \\
\text { homes and other } \\
\text { Faith-based } \\
\text { centers }\end{array}$ & 1 & 10 & $11(16.4)$ & & \\
\hline Total $^{\mathrm{a}}$ & $\begin{array}{l}53 \\
(79.1) \\
\end{array}$ & $14(20.9)$ & $\begin{array}{l}67 \\
(100.0)\end{array}$ & & \\
\hline
\end{tabular}

NB: Test statistics $\dagger=$ Chi-square

PPMVs = Patent and Proprietary Medicine Vendors

${ }^{a}=$ number in parentheses represent percentages across the row

${ }^{\mathrm{b}}=$ number in parentheses represent percentages along the column

\section{Post-mortem findings}

Post-mortem examination was done in only one case $(1.0 \%)$ out of the 98 BIDs. This involved a 4year old girl who died suddenly at a creche after being fed and administered some drugs for a febrile illness by the creche attendant at a private school. The case is still being litigated.

\section{Discussion}

BID represents a significant proportion of death in health care settings and recognition of such cases may influence decision making processes on health care. This study gives a report on paediatric cases of brought-indead (BID), a poorly reported occurrence in health facilities in Nigeria.

About two-thirds of the cases of BID in this study occurred among children from the lower social class. This is not surprising as previous studies have reported a direct relationship between social class and health care utilisation. ${ }^{11-14}$ Therefore, our findings might be a reflection of the influence of factors that cause delay in seeking and receiving health care among people from the low social class. These include: poverty, ignorance, misapplied cultural and religious beliefs, poor women empowerment and poor health-seeking behaviours. These factors might have resulted in primary delays in seeking health care by the caregivers of these children, culminating in late presentation for care and in the worst instances, presentation as BIDs, as demonstrated in this study.

Similarly, the preponderance of under-five children (72.4\%) among BID cases in this study is in tandem with findings from studies done in India and Zambia, where under-five children constituted $75.3 \%$ and $78.9 \%$ of cases of BIDs respectively. ${ }^{6,15}$ These findings further confirm the fact that children from this age group are very vulnerable. Although a much lower proportion of $10 \%$ was reported from Ghana, nevertheless, the study involved all age groups in the study location including the elderly. ${ }^{1}$ Under-five children are more prone to infections than older children due to their relatively poor immune status. They are also more likely to be involved in home accidents and in the setting of low social class, these factors become heightened. Hence, it is not surprising therefore, that, the majority of the BID cases in this study were under-five children thus emphasizing the need to pay more attention to the health of children, particularly of such age group.

The observation that fever was among the predominant symptoms in this study is not surprising. In most developing countries poor settings, many care-givers usually administer antipyretics to children with fever, which is a common symptom of ill health, and when the fever subsides, they may have a false belief that the child has recovered thus causing them to delay treatment until such children develop complications that put them at higher risk of dying.

That severe anaemia was the suspected leading cause of death among the cases especially the under-fives, is not surprising given that the study location is in the subSaharan Africa where anaemia from diverse causes including malaria associated severe anaemia is very common. ${ }^{16,17}$ Despite the difficulties at making firm diagnosis in this study, a few cases were strongly suspected as cerebral malaria after post-mortem lumbar puncture hence, it is possible that some of these deaths could have resulted from severe malaria which is still a major contributor to the under-five mortality in Nigeria. ${ }^{16,17}$ There is need to reduce childhood mortality from malaria through measures like the use of insecticide-treated nets, indoor spraying, early diagnosis with rapid diagnostic test kits and prompt treatment with the use of artemisinin-based combination therapy that are in place in many malaria-endemic countries. ${ }^{18}$ However, utilization of these modalities are still not optimal in Nigeria ${ }^{18-21}$ thus raising the need to investigate and identify the human, socio-economic and community factors that may be mitigating their utilization.

Acute gastroenteritis with its attendant complication was identified as the likely cause of death in about twenty percent of the cases. Although the mortality rate from acute diarrhoea in Nigeria has significantly reduced over the past three decades owed largely to the availability of oral rehydration solution, nonetheless, knowledge about home management of diarrhoea is not yet optimal among many caregivers. ${ }^{22,23}$ As reported in some studies, withdrawal of oral feeding including oral rehydration, unnecessary use of anti-motility drugs, administration of high osmolality drinks (thought to restore strength to a child who is weak from severe dehydration) and inability to recognise signs of worsening hydration status still abound in the population. ${ }^{22-24}$ These may contribute to delayed commencement of oral rehy- 
dration at home and late presentation to health facilities when necessary. Continuous and intensified efforts at creating awareness and appropriate information on home management of acute diarrhoea and recognition of danger signs will go a long way in stemming the tide of childhood mortality from acute watery diarrhoea.

About seventeen percent of the cases of BID in this study resulted from aspiration, mostly in under-fives. This might be a reflection of the dangers in the practice of force-feeding, which is still quite prevalent in some parts of Nigeria. ${ }^{25,26}$ The reduced food intake that accompanies most illnesses in children further fuels this practice. Some force-fed children aspirate the food materials or herbal preparations forced into their throats and probably died from aspiration of such contents rather than from the primary illness. ${ }^{26}$ To further compound the problem of these force-fed children, the practice of force-feeding often occur in environments where little or no immediate resuscitation helps such as airway patency maintenance and or ventilatory supports can be rendered thus precluding their chances of survival.

Equally worthy of note in the study is the number of deaths from home accidents. Most occurred in the very young age, reflecting the increased mobility, inquisitiveness and poor awareness of dangers associated with this age. Previous studies have also documented a higher prevalence of home accidents in preschool age children. ${ }^{27,28}$ It may however also be an eye-opener to poor supervision and neglect on the part of the caregivers. One rather pathetic instance among the BID was an eight-year old boy who accidentally shot his six-year old brother while playing together at home with their neighbour's Dane gun. Also, the cases of drowning and suspected pesticide and carbon monoxide poisonings from generator fumes reflect the unsafe milieu in which children from the study locality are being reared further emphasizing the need for better supervision, vigilance, and extra caution on the part of parents and caregivers in the study locality.

Despite the available opportunities for health care services delivery in the study locality, the study location being an urban area with many health facilities, some of the cases of BID in this study did not receive any form of treatment for their illnesses prior to demise. This suggests a primary delay in health care and a poor healthyseeking behaviour among caregivers of children in the study area. Previous studies done in Nigeria has also documented primary delay as the most common delay in healthcare among the population. ${ }^{29}$ Measures to reduce primary delay such as health education, free or affordable health care, and health insurance should be put in place to forestall preventable childhood deaths and reduce under-five mortality. It is also noteworthy that a significantly higher number of those who did not receive any form of treatment during illness presented as BID within 24 hours (mostly those who died from home accidents) or after 14 days of illness. This suggests that if those children had presented earlier and sought care in the appropriate place, some of them could have been successfully treated and might have survived.
A significantly larger percentage of those who received some treatment before demise used drugs, most of which were purchased over-the-counter at the PPMVs without prescription by a physician. Self-medication is quite prevalent in developing countries and has been well documented in many studies. ${ }^{30-33}$ With selfmedication, there is the likelihood of not using the right drugs and this could lead to progression of the illness. ${ }^{34}$ Furthermore, some of these self-prescribed drugs may have deleterious effects on the health of the concerned children because of their caregivers' poor understanding of the dosing, pharmacokinetics and pharmacodynamics of the drugs being administered. ${ }^{34}$ It would not be out of place to presume that the side effects of some of the drugs could have contributed to the demise of the children. One good example is the suspected case of Steven Johnson syndrome among the BIDs recorded in this study.

The two cases who had scarification had it at traditional homes where herbal medicines were also administered but more intriguing was the observation that other faithbased centres (churches \& mosques) also administered herbal medicines to their clients. This reflects the type of care offered at these alternative or unorthodox care centres. Despite the fact that most of their practices are dangerous and inimical to the health of children, yet, some caregivers patronize them perhaps out of their continued belief in them. ${ }^{35}$ Also, their easy accessibility and probably, ease of payment which allows for sundry methods such as payment by installment, and exchange of nonemonetary materials in place of cash, may, continue to drive their patronage. Therefore, there is need to formally recognize these informal health care groups for appropriate training and interventions.

Consent for post-mortem examination was given by the caregivers of only one of the BID cases in this study and perhaps, this was possible because it turned to be a medicolegal case. This observation reflects the challenges with and the decline in rates of post-mortem examination in developing countries despite its many clinical, judicial and public health benefits. ${ }^{36,37}$ Although the low consent rate in this study might be associated with the grief that the caregivers felt over the loss of a loved one, other previously identified factors responsible for the general decline in utilization of autopsyinclude cultural and religious beliefs, cost, fear of body mutilation, desire to honour the body of the deceased, and nonavailability of health personnel to perform the autopsy. ${ }^{37}$

${ }^{-39}$ These factors could be addressed so that autopsy rates can be increased in the study locality and by extension, other parts of Nigeria.

\section{Limitation of the study}

It is possible that some caregivers might have withheld some information because of fear/guilt/confusion and or grief over loss of their wards. The absence of postmortem examinations for the cases of BIDs put some limitation on the validity of the suspected cause of death 
among the patients as these were presumed. Postmortem would have established the exact causes of death correctly thereby updating epidemiology data on childhood mortality. Nevertheless, the use of verbal autopsy through systematic questioning of caregivers of the deceased children, as was done in this study, has been recognised by the WHO as largely sufficient in instances where post-mortem examination is not available or feasible. Also, this study described the burden of paediatric BID in our locality for the first time and found some important drivers of the condition needing attention.

\section{Conclusions}

This study has highlighted the prevalence and pattern of paediatric BID in a tertiary health facility in southwest Nigeria. Factors that were associated with BID in this study, included low socioeconomic status, delay in seeking health care, and unorthodox health care seeking practices by caregivers. We recommend an appraisal of existing child care policies with the aim of stemming the tide of paediatric BID menace in our environment. Community education on common causes of childhood deaths, strengthening of primary health care system, affordable and subsidized health care for children through health insurance as well as training and supervision of alternative healthcare providers (unorthodox care practitioners) would all go a long way in achieving this aim.

\section{Conflict of interest: None \\ Funding: None}

\section{References}

1. Orish VN, Ansong JY, Anagi IB, Onyeabor OS, Okorie C, Sanyaolu AO et al. Cases of brought in dead patients in the accident and emergency unit of a referral hospital in the western region of Ghana. 2014; Open Access Library Journal1: e1179. http://

dx.doi.org/10.4236/ oalib.1101179

2. Joubert J, Rao C, Bradshaw D, Dorrington RE, Vos T, Lopez AD. Characteristics, availability and uses of vital registration and other mortality data sources in post-democracy South Africa. Glob Health Action 2012;5:19263. http:// dx.doi.org/10.3402/ gha.v50.19263.

3. American College of Obstetricians and Gynecologists. The importance of vital records ans statistics for the obstetriciangynecologist. ACOG Committee Opinion No. 748. Obstet Gynecol 2018;132:e78-81.

4. Padhye SM, Lakhey B. "Brought dead"- cases of maternal mortality. Kathmandu Univ Med J 2003;1(3):184-86.

5. Adegoke O, Ajuluchukwu JN. Demographic characteristics and causes of death for persons brought in dead to emergency department of a tertiary health facility in southwest Nigeria. Niger Postgrad Med J 2019;26:45-52.
6. Yokobori Y, Matsuura J, Sugiura Y, Mutemba C, Nyahoda M, Mwango C. et al. Analysis of causes of death among brought-in-dead cases in a third -level hospital in Lusaka, Republic of Zambia, using the tariff method 2.0 for verbal autopsy: a cross-sectional study. BMC Public Health 2020;20:473. https:// doi.org/10.1186/s12889-02008575-y.

7. Nichols EK, Byass P, Chandramohan D, Clark SJ, Flaxman AD, Jakob R, et al. The WHO 2016 verbal autopsy instrument: An international standard suitable for automated analysis by Inter VA, InSilico VA, and Tariff2.0. PLoS Med 2018;15(1):e1002486. https:// doi.org/10.1371/ journal.pmed.1002468.

8. World Health Organization. Verbal autopsy standards: Ascertaining and attributing causes of death The 2012 WHO verbal autopsy instrument. Release Candidate 1. Geneva, Switzerland: World Health Organization; 2012.

Available from: http:// www.who.int/healthinfo/ statistics/ verbalautopsystandards/en/ index 2.html (Retrieved12May 2014).
9. Thomas L-M, D’Ambruoso L, Balabanova D. Verbal autopsy in health policy and systems: a literature review. BMJ Glob Health 2018;3:e000639. doi: 10.1136/bmjgh-2017-000639.

10. Oyedeji GA. Socio-economic and cultural background of hospitalized children in Ilesa. Niger J Pediatr 1985;12:1117.

11. Uzochukwu BSC, Onwujekwe OE. Socio-economic differences and health seeking behaviour for the diagnosis and treatment of malaria: a case study of four local government areas operating the $\mathrm{Ba}$ mako initiative programme in south-east Nigeria. International $J$ Equity in Health 2004;3:6. doi:10.1186/14759276-3-6.

12. Akande TM, Owoyemi JO. Healthcare-seeking behavior in Anyigba, North-central Nigeria. Res J Med Sci 2009;3 (2):47-51.

13. Adam VY, Aigbokhaode AQ. Sociodemographic factors associated with the healthcareseeking behavior of heads of houeholds in a rural community in southern Nigeria. Sahel Med J 2018;21:31-6. 
14. Bin Siddique K, Khan S, Haque S, Sizear MI, Alam A, Haque M. Socioeconomic status \& health seeking behavior of rural people: a cross sectional study in fatikchhari, Chittagong.MOJ Public Health 2016;4(4):12731.

15. Patel SK, Singh J, Singh HP, Visshwakarma K. Brought in dead cases in a tertiary care hospital in Central India. India J Crit Care 2017;21(1):62-63.

16. UNICEF. Malaria mortality as a cause of death in children under 5. Available from https:// data.unicef.org/topic/childhealth/malaria/.Retrieved $13^{\text {th }}$ March, 2020.

17. World Health Organisation. Malaria in under five. Available from https://www.who.int. Retrieved13 ${ }^{\text {th }}$ March, 2020.

18. Chukwuocha UM. Malaria control in Nigeria. Primary Health Care 2012;2:3. doi:10.4172/21671079.1000118 .

19. Orji ML, Onyire NB, ChappJumbo A, Anyawu OU, Eke CB. Perception and utilization of insecticide-treated net among caregivers of children in Abakaliki, Nigeria. Ann Afr Med 2018;17:172-77.

20. Aderibigbe SA, Olatona FA, Sogunro O, Alawode G, Babatunde OA, Onipe AI et al. Ownership and utilization of long lasting insecticide treated nets following free distribution campaign in South West Nigeria. Pan Afr Med J 2014;17:263 doi:10.11604/ pamj.2014.17.263.3927.

21. Onah IE, Adesina FP, Uweh PO, Anumba JU. Challenges of malaria elimination in Nigeria; a review. Int J Infectious Dis Therap 2017;2(4):79-85.

22. Aguwa EN, Aniebue PN, Obi IE. Management of childhood diarrhea by patent medicine vendors in Enugu north local government, southeast Nigeria. Int J Med Med Sci 2010;2 (3):88-93.
23. Ogunrinde OG, Raji T, Owolabi OA, Anigo KM. Knowledge, attitude and practice of home management of childhood diarrhoea among caregivers of under- 5 children with diarrhoeal disease in northwestern Nigeria. $J$ Trop Pediatr 2012;58(2):143-46.

24. Okoh BAN, Alex-Hart BA. Home management of diarrhoea by caregivers presenting at the diarrhoea training unit of a tertiary hospital in southern Nigeria. Br J Med Med Res 2014;4(35):5524-40.

25. Ndu IK, Ekwochi U, Osuorah CDI, Chinawa J, Asinobi I, Eze JC et al. The knowledge and practice of force-feeding among mothers and caregivers in Enugu, southeast Nigeria. Int J Trop Dis Health 2016;11 (3): 1-7.

26. Jegede AS, Ajala AS, Adejumo OP, Osunwole SO. Force feeding practice in Yoruba community of southwestern Nigeria: evidence from ethnographic research. The Anthropologist 2006;8(3):171-79.

27. Al Rumhi A, Al Awisi H, Al Buwaiqi, Al Rabaani S. Home accidents among children: a retrospective study at a tertiary care center in Oman. Oman Med J 2020;35:e85. doi:10.5001/omj.2020.03.

28. Abubakar S, Ahmed A, Farouk Z, Gadanya M, Jimoh ML. Prevalence and pattern of unintentional domestic accidents and trauma amongst children attending public hospitals in Kano, Nigeria. Sahel Med J 2018;21:6-12.

29. Chukuezi CO, Anelechi AB. Factors associated with delays in seeking medical care among educated Nigerians. Asian J Med Sci 2009;1:30-32.

30. Babatunde OA, Fadare JO, Ojo OJ, Durowade KA, Atoyebi OA, Ajayi PO et al. Selfmedication among health workers in a tertiary institution in southwest Nigeria. Pan Afr Med J 2016;24:312. doi: 10.11604/

pamj.2016.24.312.8146.
31. Ayanwale MB, Okafor IP, Odukoya OO. Self-medication among rural residents in Lagos, Nigeria. J Med Trop 2017;19:65-71.

32. Omolase CO, Adeleke OE, Afolabi AO, Afolabi OT. Self -medication amongst general outpatients in a Nigerian community hospital. Ann Ib Postgrad Med 2007;5(2);64-67.

33. Kassie AD, Bifftu BB, Mekonnen S. Self-medication practice and associated factors among adult household members in Mekel district, northeast Ethiopia, 2017. BMC Pharmacology and Toxicology 2018;19:15. https:// doi.org/10.1186/s40360-0180205-6.

34. Chouhan K, Prasad SB. Selfmedication and their consequences: a challenge to health professional. Asian J Pharm Clin Res 2016;9(2):314-17.

35. Olatunya OS, Albuquerque DM, Adekile AD, Costa FF. Evaluation of sociodemographic, clinical and laboratory markers of sickle leg ulcers among young Nigerian at a tertiary health institution.

Niger J Clin Pract 2018;21:882-7

36. Ekanem VJ, Vhriterhire CO. Relevance of clinical autopsy in medical practice in SubSaharan Africa. Sahel Med J 2015;18:49-56.

37. Atanda AT, Umar AB, Yusuf I, Imam MI, Sule AA. Autopsy and religion: A review of the literature. Sahel Med J 2016;19:119-24.

38. Oluwasola OA, Fawole OI, Otegbayo AJ, Ogun GO, Adebamowo CA, Bamogboye AE. The Autopsy: Knowledge, attitude and perceptions of doctors and relatives of the deceased. Arch Pathol Lab Med 2009; 133:78-82.

39. Yawson AE, Tette E, Tettey Y. Through the lens of the clinician: autopsy services and utilization in a large teaching hospital in Ghana. BMC Research Notes 2014;7:943. doi:10.1186/1756-0500-7943. 